\title{
DIFFERENTIAL AGING OF MEDIAN AND ULNAR SENSORY NERVE PARAMETERS
}

\author{
ROBERT A. WERNER, MD, MS, ${ }^{1,2}$ ALFRED FRANZBLAU, MD, ${ }^{2}$ HANNAH J.S. D'ARCY, MS, ${ }^{2}$ \\ BRADLEY A. EVANOFF, MD, ${ }^{3}$ and HENRY C. TONG, MD ${ }^{4}$ \\ ${ }^{1}$ Department of Physical Medicine and Rehabilitation, Veterans Administration Hospital, 2215 Fuller Road, \\ Ann Arbor, Michigan 48105, USA \\ ${ }^{2}$ Department of Environmental Health Sciences, School of Public Health, University of Michigan, Ann Arbor, Michigan, USA \\ ${ }^{3}$ Department of Medicine, Washington University School of Medicine in Saint Louis, St. Louis, Missouri, USA \\ ${ }^{4}$ Michigan Head and Spine Institute, Southfield, Michigan, USA \\ Accepted 5 July 2011
}

ABSTRACT: Introduction: Nerve conduction velocity slows and amplitude declines with aging. Methods: Median and ulnar sensory nerves were tested at the annual meetings of the American Dental Association. Seven hundred four subjects had at least two observations. The rate of change in the nerve parameters was estimated while controlling for gender, age, change in hand temperature, baseline body mass index (BMI), and change in BMI. Results: Amplitudes of the median sensory nerve action potentials decreased by $0.58 \mu \mathrm{V}$ per year, whereas conduction velocity decreased at a rate of $0.41 \mathrm{~m} / \mathrm{s}$ per year. Corresponding values for the ulnar nerve were $0.89 \mu \mathrm{V}$ and $0.29 \mathrm{~m} / \mathrm{s}$ per year. The rates of change in amplitudes did not differ, but the median nerve demonstrated a more rapid loss of conduction velocity. Conclusions: The rate of change for the median conduction velocity was higher than previously reported. The rate of change of median conduction velocity was significantly greater than for the ulnar nerve.

Muscle Nerve 45: 60-64, 2012

Nerve conduction study (NCS) parameters change with age. In infancy, the myelin matures, and the conduction velocity increases. ${ }^{1-3}$ By the age of 3 years, most nerves have reached their optimum conduction velocity. ${ }^{4}$ The conduction velocity stays stable until approximately 30 years of age and then begins a slow decline. ${ }^{4}$ The rate of change has been estimated to decline by $10 \%$ over the next three decades. ${ }^{4}$ Several studies have demonstrated that, with increasing age, there is a decreased sensory conduction velocity in normal individuals ${ }^{1,3,5-11}$; a similar relationship has been demonstrated between aging and motor conduction velocity. ${ }^{1-3,6,7,9,12}$ However, all but one of these studies used crosssectional data from multiple subjects at differing ages to infer how individual NCS parameters change over time. A cross-sectional study design is an efficient method to suggest the rate of change of nerve conduction parameters over time, but a prospective study of subjects at two or more timepoints is a more accurate method to establish the true relationship between NCS parameters and aging.

Abbreviations: BMI, body mass index; CTS, carpal tunnel syndrome; NCS, nerve conduction studies

Key words: aging, electrodiagnostic test, epidemiologic study, median nerve, nerve conduction studies, sensory nerve function, ulnar nerve

Correspondence to: R. A. Werner; e-mail: rawerner@umich.edu

(C) 2011 Wiley Periodicals, Inc.

Published online in Wiley Online Library (wileyonlinelibrary.com).

DOI 10.1002/mus.22233
The primary purpose of this study was to evaluate how sensory NCS parameters change over time within a healthy prospective cohort. We sought to determine whether the rate of change was constant over time or if the rate was dependent upon the subject's age at the onset of the study. Other factors, such as gender and body mass index, were also evaluated to determine whether they influenced the rate of change. Finally, we attempted to determine whether the rate of change in the median nerve was the same as that of the ulnar nerve, because previous work had shown that nerves at areas of focal entrapment (the median nerve at the wrist, i.e., carpal tunnel syndrome) were likely to show a more rapid decline in function over time compared with other nerves (ulnar at the wrist), where focal entrapment was not common.

\section{METHODS}

Nerve conduction studies were initially collected from a convenience sample of dentists and other dental professionals who participated in the American Dental Association annual assembly health fair where screening for carpal tunnel syndrome was performed. ${ }^{13}$ The screening was performed from 1997 through 2007 and involved over 7000 subjects. We excluded subjects with a history of diabetes or rheumatoid arthritis. Among those tested, 704 met the inclusion criteria and had repeat testing. If the subject had a history of carpal tunnel syndrome, the data from the median nerve were dropped for all observations, but the data from the ulnar nerve were retained. The protocol included electrodiagnostic testing of distal median and ulnar sensory nerve action potentials at the wrist of the dominant hand $(14 \mathrm{~cm}$, antidromic stimulation of digits 2 and 5). Some subjects were tested more than twice, and all observations were included in the analysis. Subjects completed a questionnaire that addressed demographic data (height, weight, age, gender) and medical history (diabetes mellitus, thyroid disease, rheumatoid arthritis, peripheral neuropathy). Body mass index (BMI) was 
calculated as weight divided by height squared $\left(\mathrm{kg} / \mathrm{m}^{2}\right)$.

Palm temperatures were recorded, and the hand was warmed if it was $<32^{\circ} \mathrm{C}$. The peak and onset latencies as well as the baseline-to-peak amplitudes were recorded for both the median and ulnar nerves in the dominant hand in accordance with the guidelines outlined by the American Association of Neuromuscular and Electrodiagnostic Medicine. ${ }^{14}$

Statistical Analysis. To evaluate the change in parameter values with time, a mixed model linear regression analysis was performed using SAS version 9.2 (SAS Institute, Inc., Cary, North Carolina) with Proc Mixed. In all models, the change in the NCS parameter value, as compared with baseline, was the dependent variable. Independent variables included the elapsed time between baseline and follow-up observations, the difference in hand temperatures at the two timepoints, gender, height, baseline age, baseline BMI, and change in BMI. The NCS parameters collected included sensory nerve action potential amplitude, peak latency, and onset latency, and sensory conduction velocity for the median and ulnar nerves. Subject was set as the repeated variable. As the database included measures from each subject at two or more time-points, correlations between repeated measurements were taken into account using a compound symmetry covariance structure.

To determine whether gender, age at baseline, or BMI at baseline affected the rate of change, an interaction term with elapsed time was added to the base model for each of these subject characteristics. For example, to determine whether the change over time was related to gender, an interaction term, elapsed time $\times$ gender, was added to the base model.

To determine whether any change over time was nonlinear, a quadratic term for elapsed time (time $\times$ time) was entered into the model. In addition, the quadratic term for time was considered when examining possible interactions with gender, baseline age, and baseline BMI.

To compare changes in median vs. ulnar nerve function, $95 \%$ confidence intervals were generated for the estimated rate of change per year.

\section{RESULTS}

A total of 704 subjects met the inclusion criteria, and there were a total of 1834 observations, including 1130 follow-up observations. The cohort was $80 \%$ male, and the mean age at the time of first observation was $49.4 \pm 9.5$ years. The mean BMI at baseline was $26.2 \pm 3.5 \mathrm{~kg} / \mathrm{m}^{2}$, and $11 \%$ reported a diagnosis of carpal tunnel syndrome. Table 1
Table 1. Description of study cohort.

\begin{tabular}{|c|c|c|}
\hline & $\begin{array}{l}\text { Individuals } \\
(n=704)\end{array}$ & $\begin{array}{c}\text { Follow-up } \\
\text { observations } \\
(n=1130)\end{array}$ \\
\hline \multicolumn{3}{|l|}{ Gender } \\
\hline Male & 564 (80\%) & \\
\hline Female & 140 (20\%) & \\
\hline \multicolumn{3}{|c|}{ Age at baseline (years) } \\
\hline Under 35 & $31(4 \%)$ & \\
\hline 35 to 44 & $200(28 \%)$ & \\
\hline 45 to 54 & $273(39 \%)$ & \\
\hline 55 to 64 & $152(22 \%)$ & \\
\hline 65 or older & $48(7 \%)$ & \\
\hline Mean (SD) & $49.4(9.5)$ & \\
\hline \multicolumn{3}{|l|}{ Height (inches) } \\
\hline$\leq 66$ & $150(21 \%)$ & \\
\hline$>66,<72$ & $365(52 \%)$ & \\
\hline$\geq 72$ & $186(27 \%)$ & \\
\hline $\bar{M}$ Mean (SD) & $69.1(3.6)$ & \\
\hline \multicolumn{3}{|c|}{ BMl at baseline $\left(\mathrm{kg} / \mathrm{m}^{2}\right)$} \\
\hline Under 25 & 275 (40.0\%) & \\
\hline 25 to 29.9 & 351 (49.0\%) & \\
\hline 30 or higher & $78(11.0 \%)$ & \\
\hline Mean BMI (SD) & $26.2(3.5)$ & \\
\hline \multicolumn{3}{|c|}{ CTS diagnosis at any time } \\
\hline Yes & $78(11 \%)$ & \\
\hline No & 615 (89\%) & \\
\hline \multicolumn{3}{|c|}{ Number of observations } \\
\hline 2 & $460(65 \%)$ & \\
\hline 3 & 147 (21\%) & \\
\hline 4 & $45(6 \%)$ & \\
\hline 5 & $28(4 \%)$ & \\
\hline 6 & $17(2 \%)$ & \\
\hline 7 & $5(0.7 \%)$ & \\
\hline 8 & $2(0.3 \%)$ & \\
\hline Mean (SD) & $2.6(1.1)$ & \\
\hline \multicolumn{3}{|c|}{ Number of years elapsed } \\
\hline 1 & & $164(15 \%)$ \\
\hline 2 & & $173(15 \%)$ \\
\hline 3 & & $191(17 \%)$ \\
\hline 4 & & $162(14 \%)$ \\
\hline 5 & & $153(14 \%)$ \\
\hline 6 & & $118(10 \%)$ \\
\hline 7 & & $69(6 \%)$ \\
\hline 8 & & $69(6 \%)$ \\
\hline 9 & & 31 (3\%) \\
\hline Mean (SD) & & $4.0(2.2)$ \\
\hline
\end{tabular}

describes the participants included in the study. A mean of 2.6 observations per subject was noted (range 2-8 observations). The mean time between initial and follow-up observations was 4.0 years (range 1-9 years).

Table 2 presents the baseline and last observed nerve conduction values for the median and ulnar nerves tested. For those with more than two observations, only the first and last observations are presented. The average time between the first and last observations was 4.4 years. The onset and peak latencies increased over time, whereas conduction velocity and amplitude dropped. All changes were statistically significant. 
Table 2. Mean and standard deviations of initial and final values for sensory nerve conduction measures. ${ }^{*}$

\begin{tabular}{lccrr}
\hline & $\begin{array}{c}\text { Baseline value } \\
{[\text { mean }(\mathrm{SD})]}\end{array}$ & $\begin{array}{c}\text { Final value } \\
{[\text { mean (SD)] }}\end{array}$ & $\begin{array}{r}\text { Paired } t \\
P \text {-value }\end{array}$ \\
\hline Median peak latency $(\mathrm{ms})$ & $3.42(0.42)$ & $3.53(0.43)$ & 626 & $<0.001$ \\
Median onset latency $(\mathrm{ms})$ & $2.67(0.35)$ & $2.76(0.39)$ & 610 & $<0.001$ \\
Median conduction velocity $(\mathrm{m} / \mathrm{s})$ & $53.2(6.6)$ & $51.6(6.6)$ & 610 & $<0.001$ \\
Median amplitude $(\mu \mathrm{V})$ & $26.7(11.1)$ & $24.2(10.5)$ & 626 & $<0.001$ \\
Ulnar peak latency $(\mathrm{ms})$ & $3.25(0.33)$ & $3.33(0.30)$ & 704 & $<0.001$ \\
Ulnar onset latency $(\mathrm{ms})$ & $2.55(0.30)$ & $2.58(0.27)$ & 687 & 0.002 \\
Ulnar conduction velocity $(\mathrm{m} / \mathrm{s})$ & $55.7(6.3)$ & $54.8(5.7)$ & 687 & $<0.001$ \\
Ulnar amplitude $(\mu \mathrm{V})$ & $23.6(11.2)$ & $21.6(10.7)$ & 704 & $<0.001$ \\
\hline
\end{tabular}

${ }^{*}$ Data not adjusted for hand temperature.

Table 3 presents the repeated-measures regression models of change in median and ulnar nerve conduction parameters, respectively. In models of change in median nerve conduction, quadratic time variables were not significant. When changes in ulnar nerve conduction were examined, quadratic time variables were significant for changes in conduction velocity and latency times, but not for change in amplitude. Using likelihood ratio tests and the Akaike information criterion fit statistic, we found that inclusion of the non-linear term did not improve the fit of the models for change in peak or onset latency and only very modestly improved the fit for change in conduction velocity (data not shown). In addition, the contribution of quadratic terms was quite small relative to the linear terms. For these reasons, and for ease of interpretation, we present models that include only linear terms for years elapsed.

When controlling for change in hand temperature, initial age, initial BMI, change in BMI, gender, and height, the adjusted change in nerve conduction velocity per year was $-0.41 \mathrm{~m} / \mathrm{s}$ per year for the median sensory nerve and $-0.29 \mathrm{~m} / \mathrm{s}$ per year for the ulnar sensory nerve. These rates of change differed significantly. The adjusted change

\begin{tabular}{|c|c|c|c|c|c|}
\hline \multirow[b]{2}{*}{ Dependent variable } & \multirow[b]{2}{*}{ Independent variable } & \multicolumn{2}{|c|}{ Median nerve } & \multicolumn{2}{|c|}{ Ulnar nerve } \\
\hline & & Beta & $P$ & Beta & $P$ \\
\hline \multirow[t]{7}{*}{ Change in peak latency (ms) } & Years elapsed & 0.02 & $<0.001$ & 0.01 & 0.001 \\
\hline & Change hand temp. & -0.06 & $<0.001$ & -0.07 & $<0.001$ \\
\hline & Baseline age & -0.00 & 0.758 & 0.00 & 0.848 \\
\hline & Female & -0.09 & 0.033 & -0.04 & 0.406 \\
\hline & Height (inches) & -0.01 & 0.019 & -0.00 & 0.636 \\
\hline & Baseline BMI & -0.00 & 0.615 & 0.00 & 0.911 \\
\hline & Change in BMl & 0.01 & 0.191 & -0.01 & 0.320 \\
\hline \multirow[t]{7}{*}{ Change in onset latency (ms) } & Years elapsed & 0.02 & $<0.001$ & 0.01 & 0.001 \\
\hline & Change hand temp. & -0.05 & $<0.001$ & -0.05 & $<0.001$ \\
\hline & Baseline age & 0.00 & 0.926 & 0.00 & 0.862 \\
\hline & Female & -0.07 & 0.139 & -0.05 & 0.199 \\
\hline & Height (inches) & -0.01 & 0.248 & -0.00 & 0.381 \\
\hline & Baseline BMl & -0.00 & 0.748 & -0.00 & 0.675 \\
\hline & Change in $\mathrm{BMl}$ & 0.00 & 0.772 & -0.02 & 0.056 \\
\hline \multirow[t]{7}{*}{ Change in conduction velocity $(\mathrm{m} / \mathrm{s})$} & Years elapsed & -0.41 & $<0.001$ & -0.29 & 0.001 \\
\hline & Change hand temp. & 0.97 & $<0.001$ & 1.10 & $<0.001$ \\
\hline & Baseline age & -0.00 & 0.911 & -0.01 & 0.826 \\
\hline & Female & 1.39 & 0.107 & 1.33 & 0.135 \\
\hline & Height (inches) & 0.09 & 0.300 & 0.08 & 0.380 \\
\hline & Baseline BMI & 0.05 & 0.484 & 0.04 & 0.568 \\
\hline & Change in BMl & -0.15 & 0.387 & 0.35 & 0.058 \\
\hline \multirow[t]{9}{*}{ Change in amplitude $(\mu \mathrm{V})$} & Years elapsed & -0.58 & $<0.001$ & -0.89 & $<0.001$ \\
\hline & Change hand temp. & -0.85 & 0.001 & -0.81 & 0.001 \\
\hline & Baseline age & 0.01 & 0.794 & -0.03 & 0.485 \\
\hline & Female & 2.54 & 0.149 & -0.78 & 0.528 \\
\hline & Female $\times$ years & -0.63 & 0.037 & -0.10 & 0.451 \\
\hline & Female $\times$ years squared & - & - & 0.14 & 0.169 \\
\hline & Height (inches) & 0.05 & 0.732 & -0.10 & 0.685 \\
\hline & Baseline BMI & -0.05 & 0.623 & 0.01 & 0.001 \\
\hline & Change in BMI & -0.33 & 0.178 & -0.07 & $<0.001$ \\
\hline
\end{tabular}


Table 4. Repeated-measures regression models for median sensory amplitude, stratified by gender.

\begin{tabular}{lllllrr}
\hline & & \multicolumn{2}{c}{ Men $(n=763)$} & & \multicolumn{2}{c}{ Women $(n=187)$} \\
Dependent variable & Independent variable & & Beta & $P$ & & Beta \\
\hline Change in median amplitude & Years elapsed & -0.54 & $<0.001$ & & -1.35 & $<0.001$ \\
& Change hand temp. & -0.61 & 0.016 & -1.71 & 0.016 \\
& Baseline age & 0.02 & 0.569 & -0.03 & 0.795 \\
& Height (inches) & 0.15 & 0.269 & -0.35 & 0.358 \\
& Baseline BMl & -0.04 & 0.715 & -0.08 & 0.796 \\
& Change in BMl & -0.55 & 0.039 & 0.38 & 0.538 \\
\hline
\end{tabular}

in amplitude was a decrease of $0.70 \mu \mathrm{V}$ per year for the median nerve when the whole sample was used, but this rate of change varied significantly by gender $(P=0.03)$. When separate models for men and women were performed, median sensory amplitude declined by $0.54 \mu \mathrm{V}$ per year among men, and $1.35 \mu \mathrm{V}$ among women (see Table 4). However, the decrement of rate of $0.89 \mu \mathrm{V}$ per year in ulnar sensory amplitude did not depend on gender. When the rates of decline in median and ulnar amplitude were compared, whether using the whole sample or stratifying by gender, no significant difference was found.

As expected, change in hand temperature was a significant factor in all models. Initial age, baseline BMI, and the change in BMI were never significant for any nerve measure. Height was unrelated to change in nerve function with the exception of median peak latency, where taller participants exhibited slightly less slowing.

The rate of change in nerve function per year did not depend on baseline age, baseline BMI, or height for any of the nerve function measures. Only the change in median amplitude differed significantly by gender.

Because there was a possibility that subjects with carpal tunnel syndrome (CTS) could have influenced the ulnar nerve measures as well, we ran the analysis dropping both the median and ulnar nerve conduction studies for subjects with CTS. There was no influence on the results when the ulnar nerve data were also dropped for these subjects (data not shown).

\section{DISCUSSION}

The use of a longitudinal study allows us to examine changes in nerve conduction parameters related to aging, avoiding the confounding of age and cohort that may occur with cross-sectional studies. We used data gathered from each subject at multiple time-points to estimate the change in NCS parameters over time.

This study confirms that sensory NCS parameters do change with time. The primary relationship between changes in NCS and time was linear. However, we found that both time and time squared were significantly related to changes in the speed, although not the amplitude, of ulnar nerve conduction. Thus, there appears to be a non-linear relationship, as suggested by Taylor. ${ }^{15}$ Specifically, the quadratic terms suggest that the slowing of ulnar nerve conduction is not steady, but accelerates with time. However, because the change in nerve conduction is primarily linear, and allowing for non-linearity adds little or nothing to the fit of the model yet complicates interpretation, we found it appropriate to focus on models that contained only linear change over time. This is similar to the finding reported by Tong et al., ${ }^{11}$ which was also a longitudinal study.

The conduction velocity of the ulnar sensory nerve was decreased by $0.29 \mathrm{~m} / \mathrm{s}$ per year, whereas the median nerve showed a decrease of $0.41 \mathrm{~m} / \mathrm{s}$ per year. These are significantly higher than the change in conduction velocity noted in three previous cross-sectional studies of the relationship between age and the median and ulnar sensory conduction velocity. ${ }^{1,6,9}$ Dorfman et al., ${ }^{1}$ in a small study of 30 normal subjects (15 young and 15 older adults), demonstrated a decrease of $0.16 \mathrm{~m} /$ $\mathrm{s}$ per year for the median nerve. Stetson et al. ${ }^{9}$ observed a decrease of $0.13 \mathrm{~m} / \mathrm{s}$ per year for median and $0.099 \mathrm{~m} / \mathrm{s}$ per year for ulnar nerve in their study of 105 assembly workers. The largest cross-sectional study by Letz and Gerr $^{6}$ of $>4000$ veterans demonstrated a decrease of $0.13 \mathrm{~m} / \mathrm{s}$ per year for median and $0.16 \mathrm{~m} / \mathrm{s}$ per year for ulnar nerve. Tong et al. ${ }^{11}$ noted a decrease in conduction velocity of $0.21 \mathrm{~m} / \mathrm{s}$ per year for the median sensory nerve and $0.14 \mathrm{~m} / \mathrm{s}$ for the ulnar sensory nerve in their longitudinal study of $>400$ workers.

We had hypothesized that older subjects would have a more rapid rate of decline in conduction velocity, but this was not supported by the data. We thought that decreased physiological functioning associated with increasing age would influence the rate of change in nerve conduction. ${ }^{16,17}$

Our study demonstrated that the median sensory nerve conduction velocity decreased at a greater rate than the ulnar sensory conduction velocity. The rate of change in median and ulnar amplitude, however, did not differ significantly. The differential rate of change in the median sensory 
nerve conduction velocity across the wrist, which is the most common site of nerve entrapment, was consistent with several other studies but does not identify a causative factor. The more rapid rate of decline in the median nerve may be related to higher intracarpal canal pressures with contact stress and awkward wrist postures, which place this nerve at risk for a focal entrapment. ${ }^{18,19}$

This study has several strengths including its prospective study design and sample size of $>700$ subjects. The use of a repeated-measures analysis allowed use of multiple data points on individual subjects while controlling for gender, baseline age, height, baseline BMI, change in BMI, and change in hand temperature.

There are several limitations of the study that should be considered. We only evaluated sensory nerves in the dominant hand. The results may not be as applicable to other nerves in the legs, nondominant hand, or motor nerves. The selection process was not random, and this self-selected sample may have introduced hidden biases. A longer mean follow-up period would likely provide a more accurate estimation of nerve conduction parameter changes. Our cohort of dentists and dental hygienists perform hand-intensive activities and, as such, may not be representative of the general population. Although we did not analyze the physical stresses at work (e.g., repetitive or forceful hand exertions) previous studies have shown that dentists and dental hygienists perform repetitive, highforce work, often in awkward postures. ${ }^{13,20}$ Work exposures may have contributed to the more rapid rate of decline noted in this population compared with previous studies, although we did not measure these physical stressors. Further study in other populations will be necessary to confirm our findings.

\section{REFERENCES}

1. Dorfman LJ, Bosley TM. Age-related changes in peripheral and central nerve conduction in man. Neurology 1979;29:38-44.

2. Ganeriwal SK, Reddy BV, Surdi AD, Kowale AN, Zawar PB. Influence of age on motor nerve conduction. Indian J Physiol Pharmacol 1983; 27:337-341.

3. Rivner MH, Swift TR, Malik K. Influence of age and height on nerve conduction. Muscle Nerve 2001;24:1134-1141.

4. Kimura J. Electrodiagnosis in diseases of nerve and muscle: principles and practice, 2nd ed. Philadelphia: F.A. Davis; 1989. p 99-100.

5. LaFratta CW, Zalis A. Age effects on sural nerve conduction velocity. Arch Phys Med Rehabil 1973;54:475-477.

6. Letz R, Gerr F. Covariates of human peripheral nerve function: I. Nerve conduction velocity and amplitude. Neurotoxicol Teratol 1994;16:95-104.

7. Mackenzie RA, Phillips LH II. Changes in peripheral and central nerve conduction with aging. Clin Exp Neurol 1981;18:109-116.

8. Salerno DF, Franzblau A, Werner RA, Bromberg MB, Armstrong TJ Albers JW. Median and ulnar nerve conduction studies among workers: normative values. Muscle Nerve 1998;21:999-1005.

9. Stetson DS, Albers JW, Silverstein BA, Wolfe RA. Effects of age, sex, and anthropometric factors on nerve conduction measures. Muscle Nerve 1992;15:1095-1104

10. Trojaborg WT, Moon A, Andersen BB, Trojaborg NS. Sural nerve conduction parameters in normal subjects related to age, gender, temperature, and height: a reappraisal. Muscle Nerve 1992;15: 666-671.

11. Tong H, Werner RA, Franzblau A. The effect of aging on sensory nerve conduction study parameters. Muscle Nerve 2004:29:716-720.

12. Lucci RM. The effects of age on motor-nerve conduction velocity Phys Ther 1969;49:973-976.

13. Hamann C, Werner RA, Franzblau A, Rodgers PA, Siew C, Gruninger S. Prevalence of carpal tunnel syndrome and median mononeuropathy among dentists. J Am Dent Assoc 2001;132:163-170.

14. Practice parameter for electrodiagnostic studies in carpal tunnel syndrome: summary statement. American Association of Electrodiagnostic Medicine, American Academy of Neurology, American Academy of Physical Medicine and Rehabilitation. Muscle Nerve 1993;16: 1390-1391.

15. Tavlor PK. Non-linear effects of age on nerve conduction in adults. J Neurol Sci 1984;66:223-234.

16. Carlson BM. Muscle regeneration and aging. Monogr Dev Biol 1992 23:189-195.

17. Spirduso WW. Physical dimensions of aging. Champaign, IL: Human Kinetics; 1995

18. Luchetti R, Schoenhuber R, Nathan P. Correlation of segmental carpal tunnel pressures with changes in hand and wrist positions in patients with carpal tunnel syndrome and controls. J Hand Surg [Br] 1998;23:598-602.

19. Szabo RM, Chidgey LK. Stress carpal tunnel pressures in patients with carpal tunnel syndrome and normal patients. J Hand Surg [Am] 1989;14:624-627.

20. Werner RA, Hamann C, Franzblau A, Rodgers P. Prevalence of carpal tunnel syndrome and upper extremity tendonitis among dental hygienists. J Dent Hygiene 2002;76:126-132. 